\title{
EDITORIAL
}

\section{In This Issue: Views from Above and Below}

\author{
Kurt C. Stange, $M D, P b D$, Editor
}

Ann Fam Med 2015;13:302-303. doi: 10.1370/afm.1825.

$\mathrm{A}$ $\mathrm{n}$ interesting array of articles in this issue provides both high-level and on-the-ground perspectives on how policy and particulars interact to affect health.

Two articles identify novel risk factors. Chou and colleagues use a nationwide database to discover that sleep apnea more than doubles the risk of subsequently developing panic disorder. ${ }^{1}$ Using a nationally representative database, Skeldon et al find that erectile dysfunction, already known to be a marker for future cardiovascular disease, doubles the odds of having undiagnosed diabetes. ${ }^{2}$ For an average middle-aged man, the probability of undiagnosed diabetes jumps from 1 in 50 to 1 in 10 in men with erectile dysfunction.

A nationally representative study of women aged 28 to 84 years examines sexual activity and satisfaction in mid-life and older women. ${ }^{3}$ Among older women who are sexually active, sexual satisfaction is not related to age, but to higher relationship satisfaction, better communication, and higher importance placed on sex.

Bupropion, a drug with a favorable side-effect profile that often is helpful in treating depression and for quitting smoking, also has abuse potential, mimicking crack cocaine or amphetamines when crushed and snorted or injected. Steele and colleagues find evidence of a dramatic increase in duplicitous prescriptions for bupropion in Ontario between 2000 and 2013, suggesting a need for prescribing vigilance against growing misuse. ${ }^{4}$

A mixed methods study explores barriers to implementing HPV vaccinations. ${ }^{5}$ Tailoring counseling strategies and tracking/distributing patient reminders are among the challenges faced by primary care clinicians.

Using data from a novel policy experiment and a network of community health centers, Bailey and colleagues find that patients randomly assigned to apply for Medicaid use a wider variety of services than do uninsured patients, suggesting the need for growing support of primary care for the underserved. ${ }^{6}$

Another policy analysis finds that compensation arrangements are similar for primary care physicians in and outside of accountable care organizations, but physician compensation by salary is higher in practices that bear at least some financial risk. The many evolv- ing payment changes represent a large, uncontrolled experiment worthy of ongoing evaluation. ${ }^{7}$

A special report form Tiperneni et al proposes using lessons from community-oriented primary care to move from the current narrowly health care-focused accountable care organizations toward "accountable communities for health" that address health from a community perspective that includes the total investment in health across all sectors. ${ }^{8}$ This approach is more inclusive of the diverse determinants of health, and thus has much greater potential to improve population health than that of current accountable care organizations.

An unintended consequence from a well-meaning and evidence-based clinical guideline change is examined by Ruffin et al in a study featured in Annals Journal Club. ${ }^{9}$ The authors find a dramatic reduction in chlamydia screening among young women after guidelines changed recommend beginningcervical cancer screening at age $21 .^{10}$

Another study is interesting because it brings together both patient and staff experiences in primary care for people with chronic illnesses and either no insurance or Medicaid. Both patients and staff members highly value personal relationships, but find information flow and misaligned goals and expectations to be challenges. ${ }^{11}$

A research brief describes the development and validation of online medical database search filters to identify research studies of relevance to family medicine. Two filters balance specificity and sensitivity. ${ }^{12}$

A series of insightful essays make real the importance of access and relationships for health care and health ${ }_{,}^{13}$ the value of openness to teachable moments, ${ }_{1}^{14}$ and the potential of integration into primary care to make genomic medicine helpful to patients. ${ }^{15}$

We welcome your reflections at AnnFamMed.org.

\section{References}

1. Yi-Fung Su V, Chen Y-T, Lin W-C, et al. Sleep apnea and risk of panic disorder. Ann Fam Med. 2015;13(4):325-330.

2. Skeldon SC, Detsky AS, Goldenberg SL, Law MR. Erectile dysfunction and the presence of undiagnosed type 2 diabetes, hypertension and hypercholesterolemia. Ann Fam Med. 2015;13(4):342-346. 
3. Thomas HN, Hess R, Thurston R. Correlates of sexual activity and satisfaction in midlife and older women. Ann Fam Med. 2015;13(4): 331-337.

4. Sussman AL, Helitzer D, Bennett A, Solares A, Lanoue M, Getrich CM. Catching up with the HPV vaccine: challenges and opportunities in primary care. Ann Fam Med. 2015;13(4):354-360.

5. Steele LS, Macdonald EM, Gomes T, et al. Rates of anomalous bupropion prescriptions in Ontario, Canada. Ann Fam Med. 2015;13(4): 343-346.

6. DeVoe JE, Marino M, Gold R, et al. Community health center use after Oregon's randomized Medicaid experiment. Ann Fam Med. 2015;13(4):312-320.

7. Ryan AM, Shortell SM, Ramsay PP, Casalino LP. Salary and quality compensation for physician practices participating in accountable care organizations. Ann Fam Med. 2015;13(4):321-324.

8. Tipirneni R, Vickery KD, Ehlinger EP. Accountable communities for health: moving from providing accountable care to creating health. Ann Fam Med. 2015;13(4):367-369.
9. Stange KC. Possible unintended consequence of an evidence-based clinical policy change. Ann Fam Med. 2015;13(4):iii.

10. Ursu A, Sen A, Ruffin MT. Impact of cervical cancer screening guidelines on screening for chlamydia. Ann Fam Med. 2015;13(4): 361-363.

11. Brown EJ, Kangovi S, Sha C, et al. Exploring the patient and staff experience with the process of primary care. Ann Fam Med. 2015; 13(4):347-353.

12. Pols DHJ, Bramer WM, Bindels PJE, van de Laar FA, Bohnen AM. Development and validation of search filters to identify articles on family medicine in online medical databases. Ann Fam Med. 2015; 13(4):364-366.

13. Goldstein AO. Affordable care? Ann Fam Med. 2015;13(4):370-372.

14. Selwyn PA. Openings. Ann Fam Med. 2015;13(4):381-383.

15. David SP, Johnson SG, Berger AC, et al. Making personalized health care even more personalized: insights from activities of the IOM genomics roundtable. Ann Fam Med. 2015;13(4):373-380.

\title{
EDITORIAL
}

\section{The Foundational and Urgent Importance of a Shared Primary Care Data Model}

\author{
Larry A. Green, $M D^{1}$ \\ Michael Klinkman, $M D, M S^{2}$ \\ 'Department of Family Medicine, University of Colorado, Denver, Colorado \\ ${ }^{2}$ Department of Family Medicine, University of Michigan, Ann Arbor, Michigan
}

Ann Fam Med 2015;13:303-311. doi: 10.1370/afm.1817.

$\mathrm{T}$ he purpose of this commentary is to inspire a coordinated effort by primary care leaders, communities, and health information technology (IT) experts to establish a conceptual primary care data model. A shared data model is necessary to guide the development of health IT standards that will enable primary care clinicians to make essential, foundational contributions within redesigned systems of care, education, and research. This work requires that we understand the core functions of primary care in a transformed US health care system.

Primary care provides integrated, accessible health care by clinicians who are accountable for addressing most personal health care needs, developing a sustained partnership with patients, and practicing in the context of family and community. ${ }^{1}$ The role of primary care is complex, with well-defined attributes that can serve as the foundation of health care delivery systems. As a service, primary care can be expected to improve individual and population health, the quality of health care, and the efficiency and affordability of health care, as well as relieve inequities in health and health care. ${ }^{2-4} \mathrm{~A}$ jurisdiction with weak primary care would be expected to have comparatively worse health and health care, be unnecessarily expensive, and result in substantial disparities in health and health care within its population-as is the case for the United States. ${ }^{5,6}$

All problems concerning health and health care may exist in primary care and are accepted and managed in partnerships with individuals, families, com-

Conflicts of interest: author reports none.

\section{CORRESPONDING AUTHOR}

Michael S. Klinkman, MD, MS

Department of Family Medicine

University of Michigan Health System

1018 Fuller Street

Ann Arbor, MI 48103-1213

mklinkma@umich.edu 